\title{
Traumatic Brain Injury, Aging and Reaction Time
}

\author{
D.T. Stuss, L.L. Stethem, T.W. Picton, E.E. Leech and G. Pelchat
}

\begin{abstract}
The effects of traumatic brain injury (TBI) and aging were compared on tests of simple and complex reaction time (RT). Simple RT was not significantly affected by aging or TBI. TBI patients, however, tended to be slower on Simple RT tasks, and had a larger standard deviation. Individuals over age 60 and patients of any age with TBI demonstrated slower RT with choice RT tests. In addition, both groups (those over 60 and TBI patients) were less able than other groups to inhibit the processing of redundant information. For the TBI patients, this occurred primarily on reassessment. These results suggest that the deficit in both aging and TBI is not only a generalized neuronal slowing but a more specific impairment in attentional control processes, exhibited as a deficit in focused attention.
\end{abstract}

RÉSUMÉ: Lésion cérébrale traumatique, vieillissement et temps de réaction Nous avons comparé les effets de lésions cérébrales traumatiques (LCT) et du vieillissement par des épreuves du temps de réaction (TR) simple et complexe. Le TR simple n'était pas affecté de façon significative par le vieillissement ou par une LCT. Cependant, les patients avec LCT avaient tendance à être plus lents dans les épreuves de TR simple et avaient un écart type plus considérable. Les individus au-dessus de 60 ans ainsi que les patients de tous âges avec LCT manifestaient un TR plus lent dans certaines épreuves TR. De plus, les deux groupes (les individus de plus de 60 ans et les patients) étaient moins aptes que les autres groupes à inhiber le traitement d'informations redondantes. Dans le cas des patients avec LCT, ceci survenait surtout lors de la réévaluation. Ces résultats suggèrent que le déficit dans le vieillissement et la LCT n'est pas seulement un ralentissement neuronal généralisé, mais aussi une altération plus spécifique du processus de contrôle de l'attention, manifesté par un déficit de l'attention focalisée.

Can. J. Neurol. Sci. 1989:16:161-167

Aging and traumatic brain injury (TBI) appear to have some similar effects on complex information processing. With advancing age there is a behavioral slowing, the degree of slowing being a function of task complexity. ${ }^{1-3}$ TBI also causes slowing of reaction time (RT). ${ }^{4-6}$ The slowing varies with task complexity and complex choice RT best reflects the severity of $\mathrm{TBI}^{7-11}$. Gronwall, 12 describing the performance of patients with mild head injury, suggested that "these difficulties are similar to those a 65-year man would have if suddenly confronted with the work schedule he had coped with at $25^{\prime \prime}$ (p. 372).

There appear to be at least broad similarities between aging and TBI in their effect on the brain. Severe TBI results in widespread brain damage; $13-14$ aging also causes diffuse loss of neurons. ${ }^{15-16}$ Both aging and TBI may cause focal frontal lobe dysfunction. The frontal lobes are particularly sensitive to damage by the inertial effects of TBI.13,17-20 Neuropsychological tests $21-23$ and blood flow studies 24 both suggest frontal lobe dysfunction with increasing age, although these findings are not as clear cut as those for TBI. 25
To our knowledge there has been no direct comparison of these two populations. Investigation of possible parallels is important. It would establish a rationale for longitudinal investigations of TBI individuals to see if there is acceleration of deficits with increasing age.

This paper reports the results of an experiment to compare directly the effects of TBl and aging on complex reaction time tasks. The effects of aging were evaluated by comparing three groups of subjects with ages $20-29,40-49$, and $60-69$ years. The effects of TBI were evaluated by comparing 26 subjects with varying degrees of severity of closed head injury to control subjects matched for age, education and sex. Wc also directly compared the TBI group with the three different age groups. Simple and choice RT tasks increasing in complexity were administered. In addition, subjects were compared in their ability to ignore redundant information during a choice RT task. An inability to ignore extraneous information has been described as a specific sign of frontal lobe dysfunction. 26 We hypothesized that, compared to normal young subjects, individuals over age

From the Schools of Medicine (Neurology) and Psychology, University of Ottawa; Human Neurosciences Research Unit, University of Ottawa; Ottawa General Hospital, Ottawa

Received June 9, 1988. Accepted in final form October 25, 1988

Reprint requests to: Dr. D.T. Stuss, Rotman Research Institute of Baycrest Centre, 3560 Bathurst St., Toronto, Ontario, Canada M6A 2EI 
60 and patients with TBI would both (1) show a decreased speed of information processing for complex tasks, and (2) be less capable of ignoring redundant information, a deficit in focused attention.

\section{METHODS}

\section{Study-1 - Aging}

Sixty subjects (33 males, 27 females) were recruited from the community through personal contacts or through organizations such as the Seniors Employment Bureau and the Youth Employment Agency. There were 20 subjects in each of 3 groups, with each group spanning a decade. Table 1 outlines the major characteristics of the groups. All subjects had normal or corrected-to-normal vision, and no evidence of color blindness. None had a history of neurological and/or psychiatric disorders.

\section{Study 2 - Traumatic Brain Injury}

Twenty-six outpatients with varying degrees of TBI, aged 17-57 years, participated in the research. The criteria for inclusion were hospitalization for treatment of TBI, no color blindness, and a willingness to cooperate in the project. Length of time post-injury ranged from 2-144 months. Thirteen patients were tested within 12 months of injury, 8 between 12 and 36 and 5 tested more than 36 months post-injury. The severity of the TBI was characterized by the following clinical criteria: Glascow Coma Scale (GCS), duration of post-traumatic amnesia (defined as the time from injury onset to the return of memory for daily events [orientation]), coma duration, Ommaya and Gennarelli's 27 clinical classification, and the presence or absence of a focal or diffuse mass injury as defined by CT Scan. Of the 26 TBI patients, 18 were judged on a clinical basis to require a CT scan. Of these, 9 had an abnormal CT scan, of which 6 revealed a mass lesion and 3 had a focal lesion. The major clinical characteristics of the TBI patients are outlined in Table 2. Patients were matched for age $(+/-3 \mathrm{yrs})$, sex and education (+/- 2 yrs) with normal control subjects (independent from those used in study 1), none of whom had any history of. neurologic and/or psychiatric disorders (see Table 1).

\section{Tests}

\section{Apparatus}

A personal computer controlled stimuli for the Reaction Time tests. Stimuli were white or colored on a constant background of dark grey and displayed on a $35 \mathrm{~cm}$ color monitor situated $1.5 \mathrm{~m}$ from the subject. The approximate size for each stimulus was $5 \mathrm{~cm}$ square. The mean interstimulus interval was $5 \mathrm{~s}$ with a range from 4-6 s. Subjects pressed a button in their preferred hand for the Simple Reaction Time (SRT) tests; for the Multiple Choice Reaction Time (MCRT) tests, button responses were required by both hands.

\section{Reaction Time Tests}

\section{Simple Reaction Time Test (SRT)}

The subject responded as quickly as possible to the presentation of a single stimulus, randomly selected from among four designs (a circle, square, triangle or cross). All stimuli were white outlines without shading. Five practice trials were followed by 50 test trials. Mean reaction time in milliseconds was the dependent measure.

\section{Multiple Choice Reaction Time Tests (MCRT)}

Three MCRT tests were administered. In all conditions, stimuli were randomly presented. Stimuli were categorized as either "Target" or "Nontarget". The Target stimulus, randomly selected prior to test onset, had a $25 \%$ probability of presentation. The preferred hand was used in response to a Target, and the non-preferred hand for a Nontarget. For each MCRT test 10 practice trials were followed by 100 test trials. Mean reaction time for Target correct response trials was the dependent measure.

Easy Multiple Choice Reaction Time Test (MCRT EASY) Stimuli were four white geometric shapes: a circle, square, triangle and cross. There was no shading within the outline. One of the four was randomly selected as the Target, the remaining three being randomly presented as Nontarget.

Complex Multiple Choice Reaction Time Test (MCRT COMPLEX) Stimuli had 3 different components (shape, color, and orientation of the lines within the shape), each with four possible states: shape - circle, square, triangle or cross; color - red, blue, green or yellow; line orientation - vertical, horizontal, backward slanting () or forward slanting $(/)$. The Target consisted of a randomly selected combination of these states, i.e. a red square with horizontal lines. Nontargets were all stimuli that did not possess all three of the states belonging to the Target. For example, relative to the above Target, the following would be Nontargets: a blue square with horizontal lines; a red circle with vertical lines; a yellow triangle with backward slanting lines. The probability of a specific target state (eg. red, square or horizontal lines) being in a Nontarget was $50 \%$.

Table 1: Subject Characteristics in Study 1 and Study 2

\begin{tabular}{|c|c|c|c|c|c|c|c|c|c|c|c|}
\hline \multirow[b]{2}{*}{ Group } & \multirow[b]{2}{*}{$\mathbf{N}$} & \multicolumn{3}{|c|}{ Age } & \multicolumn{3}{|c|}{ Education } & \multicolumn{2}{|c|}{ Sex } & \multicolumn{2}{|c|}{ Handedness } \\
\hline & & Mean & Range & SD & Mean & Range & SD & $\mathbf{M}$ & $\mathbf{F}$ & $\mathbf{R}$ & $\mathbf{L}$ \\
\hline \multicolumn{12}{|l|}{ Study 1} \\
\hline 1 & 20 & 25 & $20-29$ & 3 & 15 & $11-18$ & 2 & 11 & 9 & 14 & 6 \\
\hline 2 & 20 & 44 & $40-49$ & 3 & 14 & $5-20$ & 4 & 9 & 11 & 19 & 1 \\
\hline 3 & 20 & 65 & $60-69$ & 3 & 14 & $10-18$ & 2 & 8 & 12 & 19 & 1 \\
\hline \multicolumn{12}{|l|}{ Study 2} \\
\hline TBI & 26 & 31 & $17-57$ & 12 & 12 & $7-20$ & 3 & 20 & 6 & 22 & 4 \\
\hline Control & 26 & 30 & $16-60$ & 12 & 13 & $5-20$ & 3 & 20 & 6 & 19 & 7 \\
\hline
\end{tabular}


Table 2: Medical Variable Distribution for the 26 TBI Patients

\begin{tabular}{lccclll}
\hline \hline Medical Variable & Mean & SD & Range & \multicolumn{3}{c}{ Distribution } \\
\hline $\begin{array}{l}\text { Glascow Coma Scale } \\
\text { (at one week) }\end{array}$ & 14 & 2 & $7-15$ & $\leq 8$ & $9-12$ & $\geq 12$ \\
$\begin{array}{c}\text { Ommaya \& Gennarelli } \\
\text { Index }\end{array}$ & 3 & 1 & $1-5$ & $\leq 3$ & $>3$ & \\
$\begin{array}{l}\text { Coma Duration } \\
\text { (days) }\end{array}$ & 6 & 16 & $0-75$ & $\begin{array}{l}\mathrm{N}=14 \\
\mathrm{~N}=12\end{array}$ & $1-7$ & $>8$ \\
$\begin{array}{c}\text { Post-traumatic } \\
\text { Amnesia (days) }\end{array}$ & 20 & 36 & $0-135$ & $<1$ & $1-6$ & $\geq 7$ \\
& & & & $\mathrm{~N}=7$ & $\mathrm{~N}=7$ & $\mathrm{~N}=9$
\end{tabular}

Redundant Multiple Choice Reaction Time Test (MCRT REDUNDANT) These stimuli appeared as complex as in the MCRT Complex condition, containing all three components. However, no state specific to the Target would ever appear in a Nontarget. For example, if the Target was a yellow cross with vertical lines, no Nontarget would be yellow, be a cross or possess vertical lines. Therefore much of the information contained in the stimuli was redundant. Subjects were clearly informed of these constraints, but they were not specifically instructed to focus on any one state. However, if the subject used this information to focus on only one stimulus state at a time (eg. the color yellow), the test reverted to the same level of difficulty as the MCRT EASY.

\section{Procedure}

Each subject was tested individually on two occasions, each testing session lasting 90 minutes. Inter-session duration was one week. Time of day was kept constant. The RT tests were presented in the order described, except that the simple RT test was administered at the end of the session as well as at the beginning. For each test the subject was told to press the button as quickly as possible without sacrificing accuracy.

\section{Analysis}

There were insufficient incorrect responses for analyses of the error reaction times. Extreme scores ("outliers"), defined as trials in which reaction times exceeded the critical value for rejection of $\mathrm{p} \leq .01$, were removed from the sample. ${ }^{28}$ Split-plot ANOVA's were performed on the remaining subject test scores. For the first study the ANOVA structure involved one betweengroup comparison of the three age-groups and two within-group comparisons of the "test" and of the "visit". For the SRT results the "test" comparison was between the SRT obtained at the beginning of the examination and that obtained at the end. For the MCRT results the "test" comparison was among the three types of MCRT (easy, complex and redundant). For the second study the ANOVA structure was the same except that the between-group comparison was between the TBI patients and the normal controls.

Results were considered significant at $\mathrm{p} \leq 0.05$. GeisserGreenhouse corrections were used to compensate for problems in homogeneity of the variance-covariance matrix. Post hoc comparisons were performed using the Newman-Keuls Method. In Study 1, Pearson product-moment correlations were done for age and education within each test and across the three groups. In Study 2 Pearson product-moment correlations analyzed the degree of association between the Control Group's results and their age and education. For the TBI group, correlations analyzed the degree of association between the performance and the severity indices. There were insufficient subjects for analyses according to CT scan results. Results were correlated between the first and second visits for each test, and between the first and second halves of each RT test on the first visit, to assess the reliability of the measures.

\section{RESULTS}

\section{Outliers and Errors}

For both studies there was no statistically significant group difference between either the number of errors made or the number of outliers removed from each group. For all groups, the percentage of errors or outliers was less than $4 \%$.

\section{Study 1 - Aging}

\section{Simple Reaction Time Tests}

There was a statistically significant Test effect of SRT [E(1. $57)=22.72, \mathrm{p}<.001]$. The RT on the second test administration was significantly slower than on the first for all groups (see Table 3).

Table 3: The Effects of Aging and TBI on Simple RT

\begin{tabular}{lllll}
\hline \hline & \multicolumn{2}{c}{ First Visit } & \multicolumn{2}{c}{ Second Visit } \\
& Mean & SD & Mean & SD \\
\hline Study 1 & & & & \\
Group 1 (20-29) & & & & \\
SRT1 & $235^{*}$ & 28 & 232 & 26 \\
SRT2 & 249 & 35 & 265 & 45 \\
Group 2 (40-49) & & & & \\
SRT1 & 232 & 28 & 225 & 31 \\
SRT2 & 243 & 50 & 249 & 42 \\
Group 3 (60-69) & & & & \\
SRT1 & 250 & 30 & 258 & 54 \\
SRT2 & 273 & 54 & 270 & 61 \\
Study 2 & & & & \\
TBI & & & & \\
SRT1 & 334 & 292 & 351 & 206 \\
SRT2 & 357 & 305 & 409 & 287 \\
& & & & \\
\hline
\end{tabular}

* Response Time in Milliseconds.

\section{Multiple Choice Reaction Time Tests - Target responses}

Target response analysis revealed a statistically significant (Group X Test X Visit) interaction $[\mathrm{F}(4,114)=3.46, \mathrm{p}<.01]$ (see Figure 1). Post hoc analysis showed that, for all 3 groups, the Complex MCRT results were significantly slower than both the Redundant and the Easy MCRT results. However, for the eldest group (Group 3), the Redundant MCRT results were also significantly slower than the Easy MCRT results. The older subjects were not as efficient in the redundancy task. These results were consistent for both visits. Across the three groups, Group 3 reacted significantly slower than both Group 1 and Group 2 at all levels of test and visit except for the Easy MCRT in the second visit where there were no significant differences. Group 2 reaction times were somewhat slower than Group 1 results. These differences did not reach significance. 


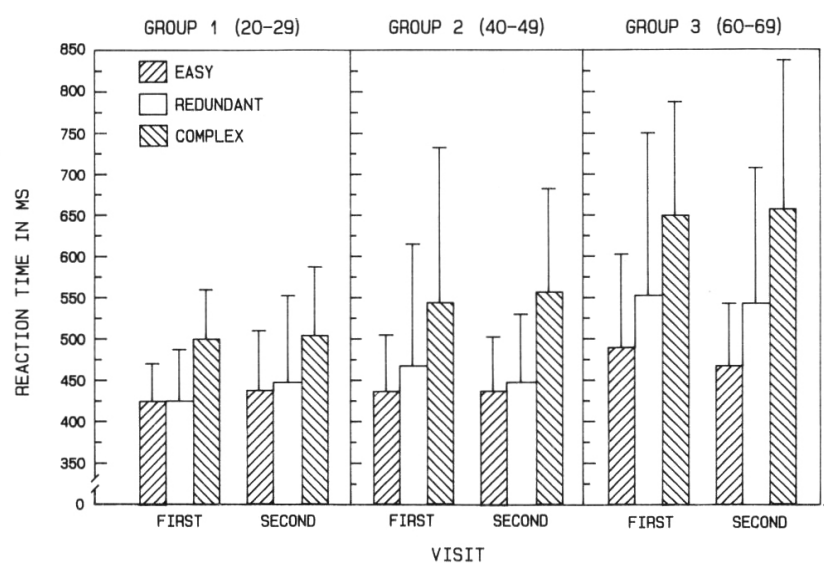

Figure I - Comparison of the three age groups for both the first and second visit on the three Multiple Choice RT tasks. Standard deviation bars illustrate the variance.

\section{Correlation Analyses}

Age correlated significantly with all MCRT tests except the MCRT Easy Target responses, accounting for between $11.4 \%$ and $20.5 \%$ of the total variance. Education did not correlate significantly with any of the RT measures. First to second visit correlations for all tests were significant at $\mathbf{p}<.001$. Split-half reliability results on the MCRT tests were significant at $p<.001$.

\section{Study 2 - Traumatic Brain Injury}

\section{Simple Reaction Time Tests}

There was no significant group effect on SRT tests although the TBI group tended to react slower than the Control group (see table 3 ). The standard deviation in the TBI group was large. For both groups a significantly slower reaction time was observed for the second visit compared to the first $[F(1,50)=7.7$, $\mathrm{p}=.008]$.

\section{Multiple Choice Reaction Time Target Responses}

For the MCRT tests, there was a statistically significant main effect of Group $[\underline{F}(1,50)=8.7, p=.005]$. Overall the TBI group reacted significantly slower than the Control group. A significant Test $X$ Visit interaction $[E(2,100)=24.5, p<.001]$ confirmed
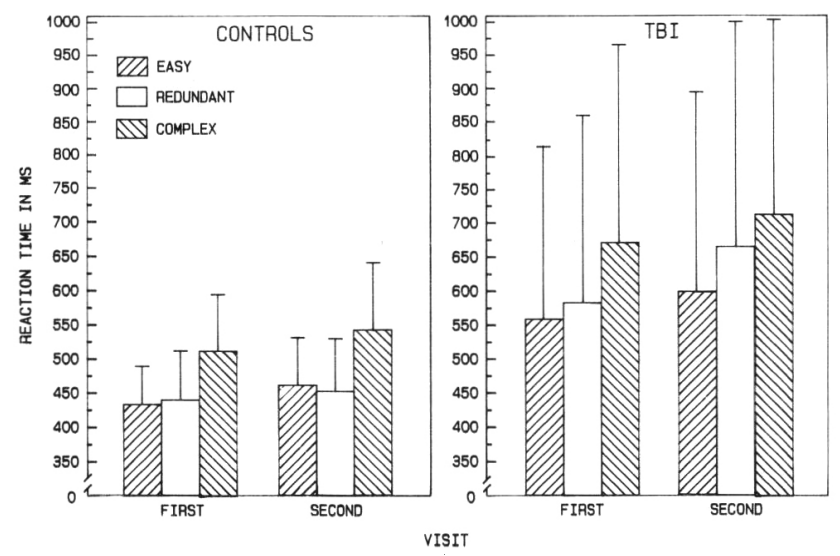

Figure 2 - Comparison of the TBI patients to their matched control subjects on the three Multiple Choice RT tasks. Standard deviation bars illustrate the variance. that MCRT Complex results were significantly different from both the MCRT Easy and Redundant results on both visits. The second visit results were significantly slower than the first visit results for all three of the MCRT tests (see Figure 2).

Within visit subanalysis revealed a significant Group $X$ Test interaction for the second visit $(\mathrm{F}(2,100)=4.34, \mathrm{p}<0.016]$. As above the TBI Group was significantly slower on all tests. Both groups reacted significantly slower on the MCRT Complex than on the MCRT Easy test. However, when the Easy and Redundant RT tests were directly compared, only the TBI group demonstrated significant slowing in response time for MCRT Redundant. For the TBI group, the mean difference between Redundant and Easy versions on the second visit was $66.7 \mathrm{~ms}$ (see figure 2). This was in contrast to the Control subjects, whose mean difference in performance between the Redundant and Easy conditions was within $10 \mathrm{~ms}$.

\section{Correlation Analyses}

Neither Age nor Education correlated significantly with any of the Control group's results. The age range was limited and did not extend past age 60.

No RT measure correlated significantly with TBI severity indices. All RT measures in the TBI group were significantly correlated with Age, explaining $30-54 \%$ of the shared variance. Education unexpectedly correlated with the first administration of the SRT test, explaining $26 \%$ of the shared variance. First to second visit correlations for all RT tests were significant at $\mathrm{p}<0.001$. All the Split-half reliability results on the MCRT tests were significant at $\mathrm{p}<0.001$.

\section{TBI vs Age Group Comparison}

To analyze the consistency of the redundancy effect, we tabulated individual difference scores. Figure 3 presents a frequency breakdown of the number of subjects in each group in Studies 1 and 2 according to the difference in ms between Redundant RT and Easy RT. The eldest age group and the TBI groups both revealed an increased number of subjects who were slow on the Redundant RT task. Chi-square analysis revealed a significant difference between the frequency of the difference scores across three levels of age and between the TBI and control subjects $(\mathrm{df}=2, \mathrm{p}<.05)$. When the eldest age and TBI groups were directly compared, there was no significant difference. Figure 3 also demonstrates that this slowing was variable in all groups.

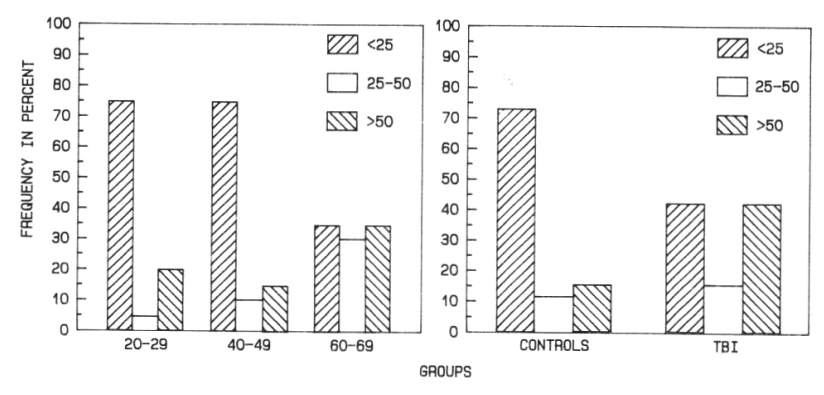

Figure 3 - Histogram of the number of subjects in each defined group based on the difference in $m s$ between the Redundant and Easy $R T$ tests. 


\section{DisCUSSION}

\section{Simple Reaction Time}

There were no significant group differences for simple reaction time for either study. The literature reports little ${ }^{3,29}$ or no $^{30}$ change with age in simple reaction time. These results also suggest that the level of motivation was comparable across the three age groups. A significant slowing for the second simple RT task and a greater variability for the second compared to the first is probably caused by fatigue. The comparison of the TBI patients to the normal control subjects did not show any significant slowing in simple reaction time. Although the overall mean for the TBI patients was approximately $100 \mathrm{msec}$ slower than the normal control subjects, the large patient variability did not result in a significant difference. This suggest that there is some change in Simple RT in at least some patients or for some trials. In summary, simple reaction time is not a sufficiently sensitive measure of the effects of either aging 30 or traumatic brain injury. 31

\section{Choice Reaction Time Tasks}

The choice RT tests clearly demonstrated a slower RT with age and with TBI, the RT correlating with the task demands. These findings corroborate previous research. ${ }^{3,29-30,32-35}$ Our results also replicated previous studies indicating that choice RT tests increasing in complexity revealed significantly slower reaction time in TBI patients. ${ }^{9-11}$

The Redundant MCRT test was designed to assess the ability of subjects to ignore extraneous information. All groups did improve on the Redundant MCRT task in comparison to the Complex MCRT task, suggesting a basic ability to focus attention. However, the TBI patients and the over age 60 subjects were less able than other groups to inhibit processing of redundant information. This effect, however, was not consistent. For example, it was observed primarily on a second visit for the TBI patients. Many subjects in the two groups did have equivalent performance on the Easy and Redundant RT tests. The correlations with the variables used in these studies do not reveal any obvious explanation for the variability. Clinically, these findings suggest that repeated assessments may be essential in uncovering specific deficits in TBI patients. Fragility in the consistent competency to focus attention may underlie certain complaints offered by these individuals, a complaint that is minimized by others because of the difficulty in objective documentation.

Similar findings have been reported in the aging literature. Older people have relatively more difficulty ignoring irrelevant information, taking a longer time to inspect the data before making a decision. ${ }^{36-37}$ It is uncertain if this occurs due to difficulty in ignoring irrelevant information, discriminating relevant from irrelevant information, or in attending to the relevant information. ${ }^{38-39}$ The elderly may be more rigid and may experience difficulty in overriding previously learned tasks and may tend to perseverate. ${ }^{23,30,40-42}$ If attention is drawn to displayed elements, the elderly have difficulty ignoring the information. 43 They use or accumulate more information than necessary to make complex discriminations. .4-45 $^{-45}$

Although in our experiment the redundant test always followed the complex, we do not believe that an inability to shift set was a factor in our experiment for the following reasons.
First, the target was different for the two conditions. The subject therefore had to use a new set of criteria to detect the target in the Redundant MCRT task. Second, the redundant nontargets were detected at a speed similar to the easy nontargets. Target detection appeared to necessitate an exhaustive search, while nontarget detection depended on serial search. The elderly could reject a blue stimulus because it was not red but could not accept a red stimulus as a target until they had confirmed that it was indeed a square filled with vertical lines (even though all red stimuli were square and had vertical lines). The elderly appear to depend to a great degree on a general "confirmation bias" or positive test strategy, ${ }^{46}$ leading to inefficient processing of target stimuli in the redundancy condition.

In the TBI literature, there is no corresponding background of similar results. A controversy has existed concerning whether a focused attention response inhibition impairment is present after TBI. These results have been inconsistent. $31.47-50$ Our results suggest that TBI patients as a group are able to meet focused attention demands and may inhibit irrelevant responses to improve performance (to their own level on the easy MCRT test), as revealed by their first visit results. This "top-down", focused attention ${ }^{51}$ is, however, completed at a cost and apparently cannot be maintained. The repeated demands of the task eventually corrodes competent performance, and the focused attention and response inhibition impairment is revealed. On the second visit the patients may decide not to or be unable to exert this amount of effort.

Based on these observations, we propose that the primary deficit in aging and TBI is not only a generalized neuronal slowing, but a more specific impairment in attentional control processes. In this regard, the inability of the elderly and the TBI patients to eliminate the processing of redundant information is similar to the known impairment of frontal lobe patients in the effective use of knowledge to regulate behavior. $26.52-55$ The frontal lobes underlie the organizational and general executive control functions of behavior, including anticipation, planning, selection of goals, holding of information in memory until the goal is obtained, and the selection of means to achieve these ends. The frontal lobes are brought into play when new or complex information is processed. The processing is slower and more deliberate. Behavioral impairments as evidenced by researching patients with focal frontal lobe lesions include difficulty in selective attention, problems in using knowledge to guide behavior, difficulties in using appropriate strategies, and poor performance of the control processing, particularly when unexpected or complex information is being processed.54-55 These functions of the frontal lobes are remarkably similar to several of the theories summarized by Salthouse ${ }^{3}$ to explain the RT slowing with aging: strategy differences, impaired internal representation of control processes, decreased capacity of working memory, and problems in concurrent processing.

Several warnings are relevant. First, not all patients revealed these deficits. There is a heterogeneity in both aging and TBI. The results also indicate heterogeneity in "normal" subjects, a source of variability too frequently overlooked. This heterogeneity in patients and control subjects must be recognized clinically, and possible causes underlying these individual differences are yet to be fully explored. Second, although the results have suggested "frontal lobe dysfunction", pathology restricted 
to the frontal lobes cannot yet be concluded. A selective decrease in aging patients in blood flow in frontal and prefrontal regions has been reported, ${ }^{24}$ but not confirmed. ${ }^{25}$ While TBI may have a predisposition for frontal lobe damage, this is not necessary and, if present, occurs against the background of more diffuse brain dysfunction. Thus, the deficit may not be one of direct frontal lobe dysfunction but may be due to impaired transformation of information from anterior to posterior brain regions secondary to white matter disorder. Moreover, whether such problems reflect intermittent arousal deficits due to brainstem dysfunction cannot be ascertained. ${ }^{56}$ Finally, we cannot exclude the possibility of an interactive explanation. Fatigue is relevant. Our RT tests were presented in a fixed order based on our original intention to have a build-up of redundant information. The second simple RT test was designed to control for possible fatigue effects. While there was no significant difference between the repeated simple RT tests, there was a tendency for the second test to be slower, particularly for the TBI patients. While fatigue may be a factor, however, it does not appear to be the sole explanation. It may contribute to the inconsistency of competent performance.

A parallel between aging and the effects of TBI has been proposed. Both groups have slower reactivities particularly in complex tasks and both have a deficit in focused attention as revealed in the redundancy task. These results stress the importance of a longitudinal study of TBI individuals to assess the possible interactive effect of aging with the effects of TBI.

\section{ACKNOWLEDGEMENTS}

Research funding was provided by the Medical Research Council of Canada. M. Lecompte typed the manuscript. G. Hamel constructed the reaction time equipment. C. Poirier and $M$. Nadon assisting in accumulating the data.

\section{REFERENCES}

1. Birren JE, Woods AM, Williams MV. Behavioral slowing with age: Causes, organization, and consequences. In: Poon LW, ed. Aging in the 1980s: Psychological issues. Washington, D.C.: American Psychological Association 1980; 293-308.

2. Cerella J, Poon LW, Williams DM. Age and the complexity hypothesis. In: Poon LW, ed. Aging in the 1980s: Psychological issues. Washington, D.C.: American Psychological Association $1980 ; 332-340$.

3. Salthouse TA. Speed of behavior and its implications for cognition. $I n$ : Birren JE, Schaie $\mathrm{KW}$, eds. Handbook of the psychology of aging. Second edition. New York: Van Nostrand Reinhold 1985; 400-426.

4. Benton AL, Blackburn HL. Practice effects in reaction time tasks in brain-injured patients. J Abnorm Soc Psychol 1958; 54: 109113.

5. Blackburn HL, Benton AL. Simple and choice reaction time in cerebral disease. Confinia Neurologica 1955; 15: 327-338.

6. Klensch H. (1973). Die diagnostische Valenz der Reaktionszeitmessung bei verschiendenen zerebralen Erkrankungen. Fortschr Neurol Psychiatr 1973; 41: 575-581 (referred in Van Zomeren \& Deelman, 1978).

7. Dencker SJ, Lofving B. A psychometric study of identical twins discordant for closed head injury. Acta Psychiatr Neurol Scand 1958; 33: 122.

8. MacFlynn G, Montgomery EA, Fenton GW, et al. Measurement of reaction time following minor head injury. $J$ Neurol Neurosurg Psychiatry 1984; 47: 1326-1331.

9. Miller E. Simple and choice reaction time following severe head injury. Cortex 1970; 6: 121-127.
10. Norrman B, Svahn K. A follow-up study of severe brain injuries. Acta Psychiatr Neurol Scand 1961; 37: 236-264.

11. Van Zomeren AH, Deelman BG. Differential effects of simple and choice reaction after closed head injury. Clin Neurol Neurosurg 1976; 79: 81-90.

12. Gronwall DMA. Paced auditory serial-addition task: A measure of recovery from concussion. Percept Mot Skills 1977; 44: 367. 373.

13. Alexander MP. Traumatic brain injury. In: Benson DF, Blumer D, eds. Psychiatric aspects of neurologic disease. New York: Grune \& Stratton 1982; 219-249.

14. Stritch SJ. The pathology of severe head injury. J Neurol Neurosurg Psychiatry 1956; 19: 163-185.

15. Kemper T. Neuroanatomical and neuropathological changes in normal aging and in dementia. In: Albert ML, ed. Clinical neurology of aging. New York: Oxford University Press 1984; 9-52.

16. Kinsbourne M. Cognitive deficit and the aging brain: A behavioral analysis. Int J Aging Hum Dev 1974; 5: 41-49.

17. Clifton GL, Grossman RG, Makela ME, et al. Neurological course and correlated computerized tomography findings after severe closed head injury. J Neurosurg 1980; 52: 619-24.

18. Courville CB. Pathology of the central nervous system. Mountain View, CA: Pacific Press, 1937.

19. Levin HS, Mattis S, Ruff RM, et al. Neurobehavioral outcome following minor head injury: a three-center study. J Neurosurg 1987; 66: 234-243.

20. Stuss DT. Contribution of frontal lobe injury to cognitive impairment after closed head injury: Methods of assessment and recent findings. In: Levin HS, Grafman J, Eisenberg HM, eds. Neurobehavioral recovery from head injury. New York: Oxford University Press 1987; 166-177.

21. Albert MS, Kaplan EF. Organic implications of neuropsychological deficits in the elderly. In: Poon LW, Fozard J, Cermak L, Arenberg D, Thompson LW, eds. New directions in memory and aging. Hillsdale, New Jersey: Lawrence Erlbaum 1980; 403-432.

22. Cummings JL, Benson DF. Dementia: A clinical approach. Boston: Butterworth 1983.

23. Moscovitch $\mathbf{M}$, Winocur G. Contextual cues and release from proactive inhibition in young and old people. Can J Psychol 1983; 37: 331-344.

24. Dupui Ph, Guell A, Bessoles G, et al. Cerebral blood flow in aging: Decrease of hyperfrontal distribution. In: Cohen MM, ed. Monographs in neural sciences. Basel: Karger 1984; 131-138.

25. Duara R, Grady C, Haxby J, et al. Human brain glucose utilization and cognitive function in relation to age. Ann Neurol 1984; 16: 702-713.

26. Luria AR. The working brain. An introduction to neuropsychology, translated by B. Haigh. New York: Basic Books 1973.

27. Ommaya AK, Gennarelli TA. Cerebral concussion and traumatic unconsciousness. Correlation of experimental and clinical observations on blunt head injuries. Brain 1974; 97: 633-654.

28. Grubbs FE. Procedures for detecting outlying observations in samples. Technometrics 1969; 11: 1-21.

29. Welford AT. Motor performance. In: Birren JE, Schaie KW, eds. Handbook of the psychology of aging. New York: Van Nostrand Reinhold 1977; 450-496.

30. Welford AT. Sensory, perceptual, and motor processes in older adults. In: Birren JE, Sloane RB, eds. Handbook of mental health and aging. Englewood Cliffs, N.J.: Prentice-Hall 1980; 192-213.

31. Van Zomeren AH. Reaction time and attention after closed head injury. Lisse: Swets \& Zeitlinger 1981.

32. Anders TR, Fozard JL. Effects of age upon retrieval from primary and secondary memory. Devel Psychol 1973; 9; 411-415.

33. Cohen G, Faulkner D. Age differences in performance on two information-processing tasks: Strategy selection and processing efficiency. J Gerontol 1983; 38: 447-454.

34. Gaylord SA, Marsh GR. Age differences in the speed of a spatial cognitive process. J Gerontol 1975; 30: 674-678.

35. Rabbitt $P$. Changes in problem solving ability in old age. I $n$ : Birren JE, Schaie KW, eds. Handbook of the psychology of aging. New York: Van Nostrand Reinhold 1977; 606-625. 
36. Griew $\mathrm{S}$. Uncertainty as a determinant of performance in relation to age. Gerontologia 1958; 2: 284-289.

37. Rabbitt PMA. An age-decrement in the ability to ignore irrelevant information. J Gerontol 1965; 20: 233-238.

38. Madden DJ. Aging and distraction by highly familiar stimuli during visual search. Dev Psychol 1983; 19: 499-507.

39. Wright LL, Elias JW. Age differences in the effects of perceptual noise. J Gerontol 1979; 34: 704-708.

40. Chown SM. Age and the rigidities. J Gerontol 1961; 16: 353-362.

41. Mistler-Lachman JL. Spontaneous shift in encoding dimensions among elderly subjects. J Gerontol 1977; 32: 68-72.

42. Schaie $\mathrm{KW}$. Intelligence and problem-solving. In: Birren JE, Sloane RB, eds. Handbook of mental health and aging. Englewood Cliffs, N.J.: Prentice-Hall 1980; 262-284.

43. Wetherick NE. Changing an established concept: A comparison of the ability of young, middle-aged and old subjects. Gerontologia 1965; 77: 89-95.

44. Howell SC. Age, familiarity and complexity as recognition variables. Percept Mot Skills 1972; 34: 732-734.

45. Rabbitt PMA. Age and the use of structure in transmitted information. In: Talland GA, ed. Human aging and behavior: Recent advances in research and theory. New York: Academic Press 1968; 75-92.

46. Klayman J, Ha Y-W. Confirmation, disconfirmation, and information in hypothesis testing. Psychol Rev 1987; 94: 211-228.

47. Chadwick O, Rutter M, Brown G, et al. A prospective study of children with head injuries: II. Cognitive sequelae. Psychol Med
1981; 11: 49-62.

48. Stuss DT, Ely P, Hugenholtz $\mathrm{H}$, et al. Subtle neuropsychological deficits in patients with good recovery after closed head injury. Neurosurgery 1985; 17: 41-47.

49. Van Zomeren AH, Brouwer WH. Head injury and concepts of attention. In: Levin HS, Grafman J, Eisenberg HM, eds. Neurobehavioral recovery from head injury. New York: Oxford University Press 1987; 398-415.

50. Van Zomeren AH, Brouwer WH, Deelman BG. Attentional deficits: The riddles of selectivity, speed, and alertness. In: Brooks N, ed. Closed head injury: Psychological, social and family consequences. Oxford: Oxford University Press 1984;: 74-107.

51. Treisman AM, Gelade G. A feature-integration theory of attention. Cognitive Psychol 1980; 12: 97-136.

52. Fuster JM. The prefrontal cortex. Anatomy, physiology, and neuropsychology of the frontal lobe. New York: Raven Press 1980.

53. Luria AR. Higher cortical functions in man, translated by B. Haigh. New York: Basic Books, 1980.

54. Stuss DT, Benson DF. Neuropsychological studies of the frontal lobes. Psychol Bull 1984; 95: 3-28.

55. Stuss DT, Benson DF. The frontal lobes. New York: Raven Press 1986.

56. Van Zomeren AH, Deelman BG. Long-term recovery of visual reaction time after closed head injury. J Neurol Neurosurg Psychiatry 1978; 41: 452-457. 